\title{
Analysis of Dynamic Load Characteristics on Hydrostatic Bearing with Variable Viscosity and Temperature using Simulation Technique
}

\author{
V. Srinivasan* \\ Professor, School of Mechanical Engineering, Bharath University, Chennai-73; srinivasan_v9669@yahoo.co.in
}

\begin{abstract}
The paper reflects the common design and calculation methods and shows their limitations in regard to the calculation of hydrostatic bearings at high velocities. It analyzes the results of complex dynamic flow simulations of hydrostatic bearings and presents a new design and optimization concept of hydrostatic bearings. This concept analyses the oil flow at high bearing velocities and it optimizes the bearing geometry, the restrictor geometry as well as the geometry of the main mechanical components.

Expressions are obtained for the temperature distribution in an externally pressurized thrust bearing for the condition when one bearing surface is rotated. The influence of centripetal acceleration and the combined effect of rotational and radial inertia terms are included in the analysis. Rotation of the bearing causes the lubricant to have a velocity component in an axial direction towards the rotating surface as it spirals radically outwards between the bearing surfaces. This results in an increase in the pumping losses and a decrease in the load capacity of the bearing. A further loss in the performance of the bearing is found when the radial inertia term in addition to the rotational inertia term is included in the analysis.

Application of hydrostatic bearings is limited by friction and therewith by velocity. Typical characteristics of the hydrostatic system (load, stiffness, flow) are calculated without a velocity dependency. The geometry of the hydrostatic bearing pockets and their restrictors are optimized by using time continuous pressure distribution at the bearing pocket, laminar flow behavior as well as constant velocity of the bearing. The dynamic effects of the flow at high velocities are not considered.

The proposed design has higher load capacity, higher stiffness and damping coefficients, lower flow rate and uniform pressure distribution by using the HTGA/Gray method. A Hydrostatic bearings test bench has been designed, built and setup. The test bench has been monitored with pressure, flow-rate, temperature, displacement and force sensors.
\end{abstract}

Keywords: Hydrostatic Bearing, Pressure, Temperature, Viscosity, Load Capacity, Damping.

\section{Introduction}

In a hydrostatic bearing, an external source of pressurized fluid forces lubricant between two surfaces, thus enabling non-contacting operation and the ability to support a load. Hydrostatic bearings can support large loads without journal rotation and provide large (accurate and controllable) direct stiffness as well as damping (energy dissipation) coefficients. Hydrostatic bearings rely on external fluid pressurization to generate load support and a large centering stiffness, even in the absence of journal rotation. The load capacity and direct stiffness of hydrostatic bearings do not depend on fluid viscosity, thus making them ideal rotor support elements in process fluid pumps. Current applications intend to replace oil lubricated bearing with hybrid bearings to improve efficiency with shorten rotor spans and less mechanical complexity. Current cryogenic liquid turbo pumps implement hydrostatic bearings enabling an all fluid film bearing technology with very low number of parts and no DN limit operation. Details on the bulk-flow

${ }^{*}$ Corresponding author:

V. Srinivasan (srinivasan_v9669@yahoo.co.in) 
analysis of turbulent flow hydrostatic bearings are given along with the discussion of performance characteristics, static and dynamic, for hydrostatic bearings supporting a water pump. Angled liquid injection produces a hydrostatic bearing with unsurpassed dynamic force and stability characteristics.

Hydrostatic bearings derive their load capacity not from shear flow driven effects (hydrodynamic wedge and surface sliding) but rather from the combination of temperature versus flow resistance effects through a feed restrictor and in the film lands. Figure 1 depicts thrust and radial hydrostatic bearing configurations for process fluid lubrication turbo pumps presents the major advantages and disadvantages of hydrostatic bearings.

The hydrostatic stiffness is of unique importance for the centering of high-precision milling machines, gyroscopes, large arena movable seating areas, telescope bearings, and even cryogenic fluid turbo pumps for rocket engines. Hydrostatic bearings require an external pressurized supply system and some type of flow restrictor. Also, under dynamic motions, hydrostatic bearings may display a pneumatic hammer effect due to fluid compressibility. However, and most importantly, the load and static stiffness of a hydrostatic bearing are independent of fluid viscosity; thus making this bearing type very attractive for application with non-viscous fluids, including gases and cryogens.

With substantially low friction, high stiffness, high accuracy, and long service life, the performance of this type of bearing is greatly affected by the recess shape during the design process and the type of restrictor. The majority of the studies employed rectangular shape of the recess. This may be because of ease of manufacturing. However, owing to rapid technological advancements in manufacturing techniques, the other recess shapes can now be easily manufactured.

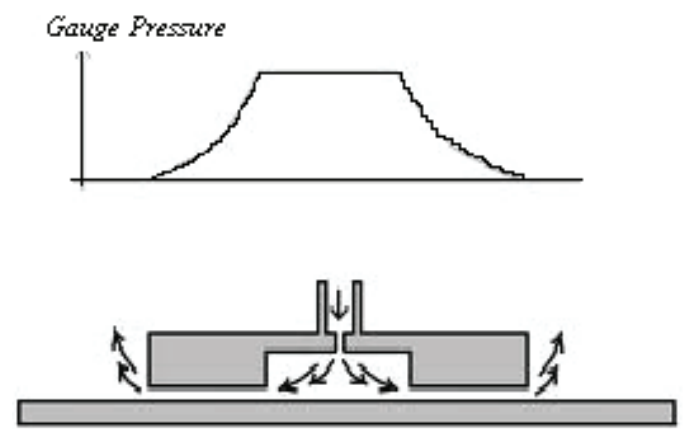

Figure 1. Bearing recess fluid flow.

\section{Modeling of a Hydrostatic Bearing}

The principle of a hydrostatic bearing fluid flow is shown in Figure 2. The hydrostatic bearing working principle is that liquid at a constant supply pressure $S P$ is pumped into the bearing. The lubricating oil is compulsively injected into the recess forms bearing capacity of hydrostatic bearing through throttling action of the gap between bearing pad and worktable. Thus, the pressure inside the recess of the bearing pad is constant and declines to the pressure along the bearing land. The resulting pressure distribution and the external load stay in equilibrium. Hydrostatic bearings test bench has been designed and set up to study the grinding machines wheel head and to validate the theoretical models. The demonstrator, Figure 3, has three hydrostatic bearings: two radials (A and B) and one axial (C).

\section{Mathematical Modeling}

Some basic assumptions are applied in this study before deriving the equation of the hydrostatic bearing. Consider a steady, we assume that the fluid properties are isotropic, incompressible and are viscous. The governing equations for this problem can be written as follows: where $p$ is the pressure distribution of the bearing, $\mu$ is the viscosity of lubricating, $\mathrm{u}, \mathrm{v}$ and $\mathrm{w}$ are three component of the velocity vector respectively along $x, y$ and $z$ axes. Eqs. (1) may be integrated twice and evaluated to determine the velocity distribution. The boundary conditions employed are $u=0$ and $v=0$ at $z=0$ or $h$. The velocity distribution is given by

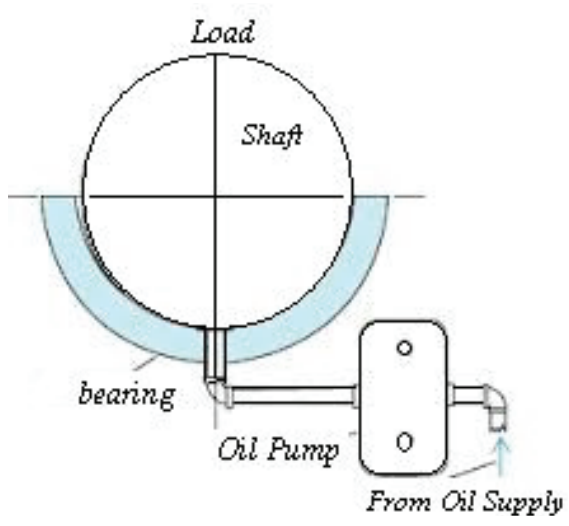

Figure 2. Lubrication for bearing. 


$$
\mathrm{K}=\mathrm{A}_{\text {effective }} \frac{\partial \Delta \mathrm{P}}{\partial \delta}=3 \mathrm{P}_{\mathrm{S}} \mathrm{A}_{\text {effective }} \mathrm{h}^{3}\left[\begin{array}{l}
\frac{(\mathrm{h}-\delta)^{2}}{\left[(\mathrm{~h}-\delta)^{3}+\mathrm{h}^{3}\right]^{2}}+ \\
\frac{(\mathrm{h}+\delta)^{2}}{\left[(\mathrm{~h}+\delta)^{3}+\mathrm{h}^{3}\right]^{2}}
\end{array}\right]
$$

\section{Hydrostatic Bearings' Theoretical Study}

Bearings lubrication theory is based in the formulation reported earlier [1-4]. This equation result applying movement quantity conservation and continuity equation to the volume control shown in the Figure 4.

The difference in pressure between the upper and lower pads of the bearing is:

- For a nominal gap h and small excursions $\delta$ of the structure:

The difference in pressure across the bearing is: If the inlet flow resistance $\mathrm{R}$ was zero, the bearing could support no load.

$$
\begin{gathered}
\Delta \mathrm{P}=\mathrm{P}_{\mathrm{u}}-\mathrm{P}_{\mathrm{l}}=\mathrm{P}_{\mathrm{s}}\left(\frac{\mathrm{R}_{\mathrm{u}}}{\mathrm{R}+\mathrm{R}_{\mathrm{u}}}-\frac{\mathrm{R}_{\mathrm{l}}}{\mathrm{R}+\mathrm{R}_{1}}\right) \\
\mathrm{R}_{\mathrm{u}}=\frac{\gamma}{(\mathrm{h}-\delta)^{3}} \quad \mathrm{R}_{\mathrm{l}}=\frac{\gamma}{(\mathrm{h}+\delta)^{3}}
\end{gathered}
$$

- If the inlet flow resistance was infinite, the bearing could support no load.

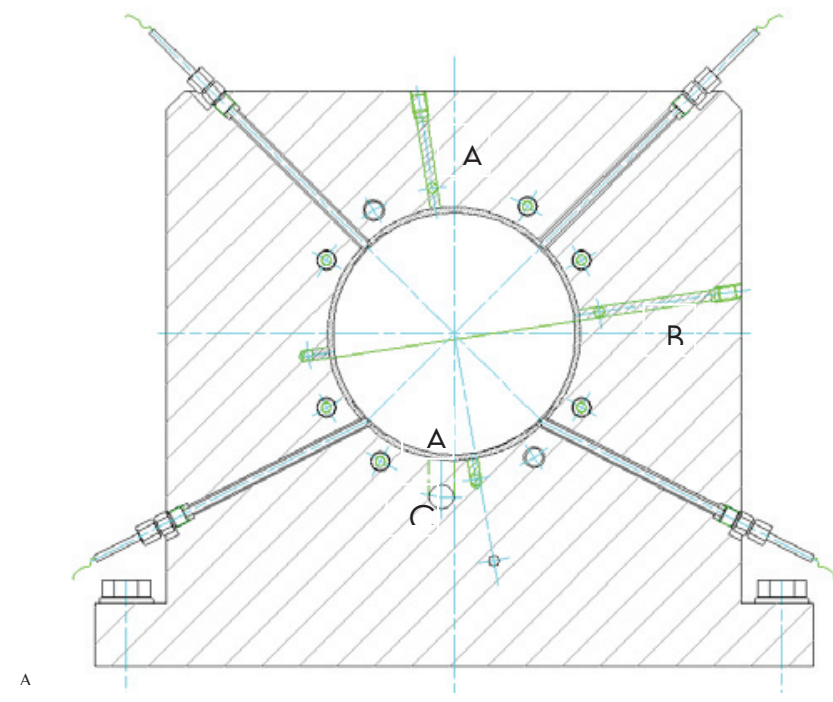

Figure 3. Three inductive sensors.

$$
\Delta \mathrm{P}=\mathrm{P}_{\mathrm{s}} \gamma\left[\frac{1}{\mathrm{R}(\mathrm{h}-\delta)^{3}+\gamma}-\frac{1}{\mathrm{R}(\mathrm{h}+\delta)^{3}+\gamma}\right]
$$

- There must be some ideal inlet resistance (compensation) between these two extremes.

$$
\frac{\partial \Delta \mathrm{P}}{\partial \mathrm{R}}=\mathrm{P}_{\mathrm{s}} \gamma \mathrm{h}^{2}\left[\frac{-(\mathrm{h}-3 \delta)}{\left[\mathrm{Rh}^{2}(\mathrm{~h}-3 \delta)+\gamma\right]^{2}}-\frac{(\mathrm{h}+3 \delta)}{\left[\mathrm{Rh}^{2}(\mathrm{~h}+3 \delta)+\gamma\right]^{2}}\right]
$$

- Taking the partial derivative of the pressure difference with respect to the inlet flow resistance; Stiffness is the change in load for a given change in bearing gap where the effective is the effective bearing area. At maximum load capacity, the bearing stiffness is high. In a hydrostatic bearing an external source of pressurized fluid forces lubricant between two surfaces, thus enabling non-contacting operation and the ability to support a load. Hydrostatic bearings can support large loads without journal rotation and provide large (accurate and controllable) direct stiffness as well as damping (energy dissipation) coefficients[5-9].

$$
\mathrm{K} \approx \frac{3 \mathrm{P}_{\mathrm{S}} \mathrm{A}_{\text {effective }}}{2 \mathrm{~h}} \approx \frac{\mathrm{F}_{\max }}{\mathrm{h}}
$$

\section{Reynolds Equation}

The physical configuration of fluid flow between two curved surfaces is shown in Figure 4. The basic equations of motion and the equation of continuity for a Newtonian

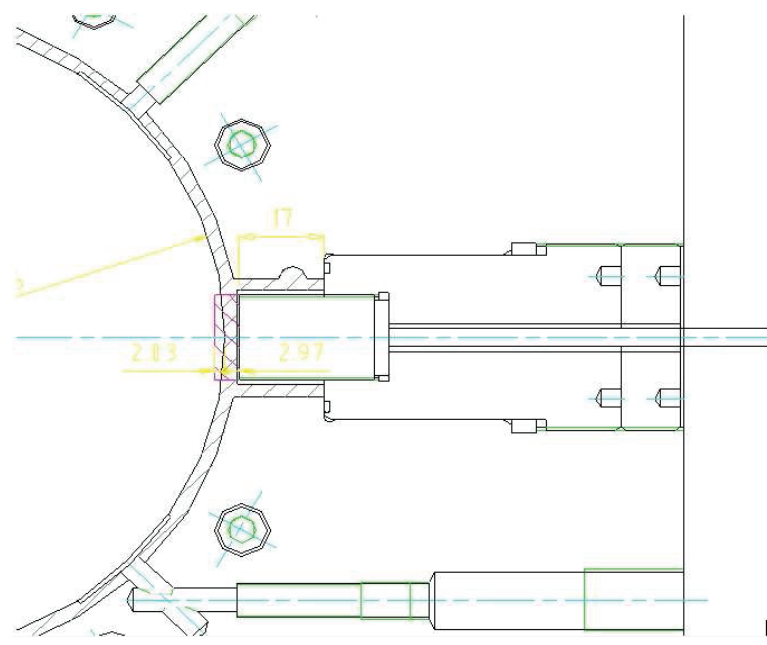

Figure 4. Measurement through bearing. 
fluid considering the variation of fluid properties both across and along the film thickness can be written as

$$
\begin{aligned}
& \rho \frac{D u}{D t}=\rho X-\frac{\partial p}{\partial x}+\frac{2}{3} \frac{\partial}{\partial x}\left\{\eta\left(\frac{\partial u}{\partial x}-\frac{\partial v}{\partial y}\right)\right\}+ \\
& \frac{2}{3} \frac{\partial}{\partial x}\left\{\eta\left(\frac{\partial u}{\partial x}-\frac{\partial w}{\partial z}\right)\right\}+ \\
& \frac{\partial}{\partial y}\left\{\eta\left(\frac{\partial v}{\partial x}+\frac{\partial u}{\partial y}\right)\right\}+\frac{\partial}{\partial z}\left\{\eta\left(\frac{\partial u}{\partial z}+\frac{\partial w}{\partial x}\right)\right\} \\
& \rho \frac{D v}{D t}=\rho Y-\frac{\partial p}{\partial y}+\frac{2}{3} \frac{\partial}{\partial y}\left\{\eta\left(\frac{\partial v}{\partial y}-\frac{\partial u}{\partial x}\right)\right\}+ \\
& \frac{2}{3} \frac{\partial}{\partial y}\left\{\eta\left(\frac{\partial v}{\partial y}-\frac{\partial w}{\partial z}\right)\right\} \\
& +\frac{\partial}{\partial z}\left\{\eta\left(\frac{\partial w}{\partial y}+\frac{\partial v}{\partial z}\right)\right\}+\frac{\partial}{\partial x}\left\{\eta\left(\frac{\partial v}{\partial x}+\frac{\partial u}{\partial y}\right)\right\} \\
& \rho \frac{D w}{D t}=\rho Z-\frac{\partial p}{\partial z}+\frac{2}{3} \frac{\partial}{\partial z}\left\{\eta\left(\frac{\partial w}{\partial z}-\frac{\partial u}{\partial x}\right)\right\}+ \\
& \frac{2}{3} \frac{\partial}{\partial z}\left\{\eta\left(\frac{\partial w}{\partial z}-\frac{\partial v}{\partial y}\right)\right\} \\
& +\frac{\partial}{\partial x}\left\{\eta\left(\frac{\partial u}{\partial z}+\frac{\partial w}{\partial x}\right)\right\}+\frac{\partial}{\partial y}\left\{\eta\left(\frac{\partial w}{\partial y}+\frac{\partial v}{\partial z}\right)\right\} \\
& \frac{\partial}{\partial x}(\rho u)+\frac{\partial}{\partial y}(\rho v)+\frac{\partial}{\partial z}(\rho w)=0
\end{aligned}
$$

With the usual assumptions of lubrication theory equations. can be simplified to

$$
\frac{\partial p}{\partial x}=\frac{\partial}{\partial z}\left(\eta \frac{\partial u}{\partial z}\right) \frac{\partial p}{\partial y}=\frac{\partial}{\partial z}\left(\eta \frac{\partial v}{\partial z}\right) \text { where } p=p(x, y) \text { is }
$$

the film pressure.

\section{Numerical Calculation of Hydrostatic Bearings}

Due to the limitations required to analytical model resolution, numerical model of hydrostatic bearings has been developed. This paper shows the results of numerical simulations carried out with the commercial software FLUENT. After modeling the bearing described in Figure 5, static calculations has been made to obtain the pressure into

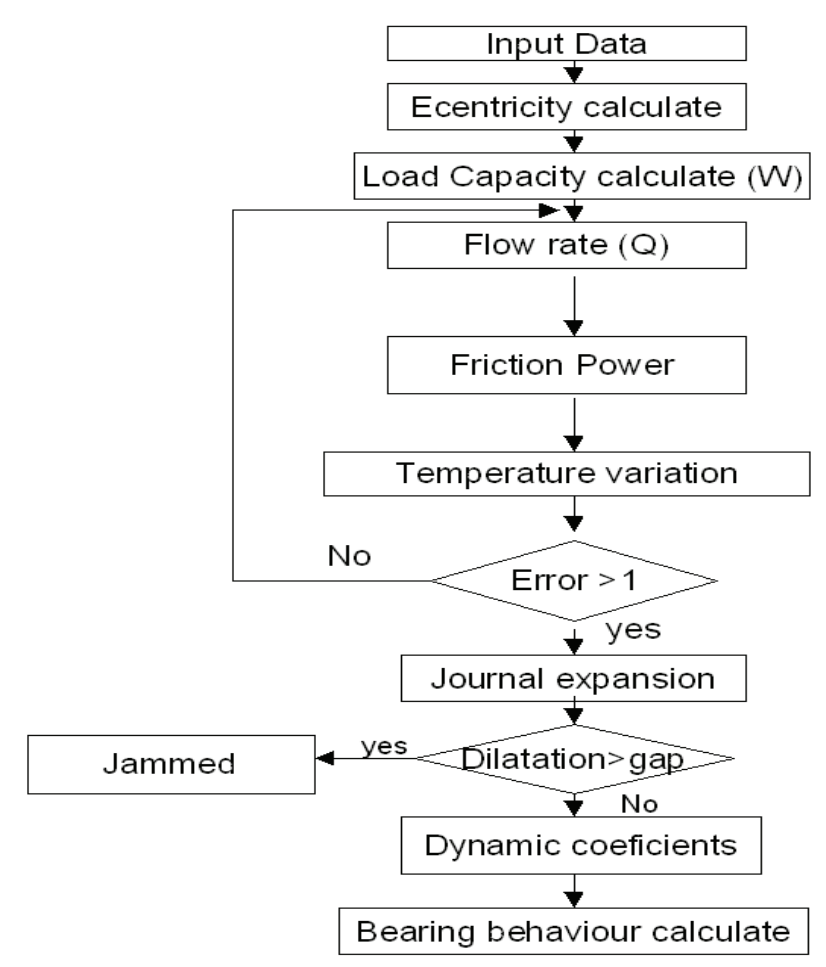

Figure 5. Flow diagram for calculation software.

recesses and the flow-rate through the bearing [10-12]. In these simulations the boundary conditions are: the supply pressure and shaft speed, while outlet pressure is atmospheric. On the other hand, lubricant properties are assumed constant for each simulation, Figure 5.

\section{Simulation Results}

The optimization approach for HTGA/Gray method is used to determine suitable parameters. The simulation results under constant parameters setting with 25 bar of supply.

(International Forum on Systems and Mechatronics, 2010) 5 pressure and $25 \mu \mathrm{m}$ of film thickness as shown in Figure 6, we can found the uniform pressure distribution of a square hydrostatic bearing via HTGA/Gray method.

The main performance characteristics of interest in the present study are load capacity, stiffness and damping coefficients and flow rate. The performance characteristics of different supply pressures and film thicknesses as shown in Figure 7. The following sections compare the performance characteristics of the proposed design with general hydrostatic bearing having recesses of different shapes shows the recess shape of a general hydrostatic bearing. Comparisons were made on the basis of the same supply pressure, film 


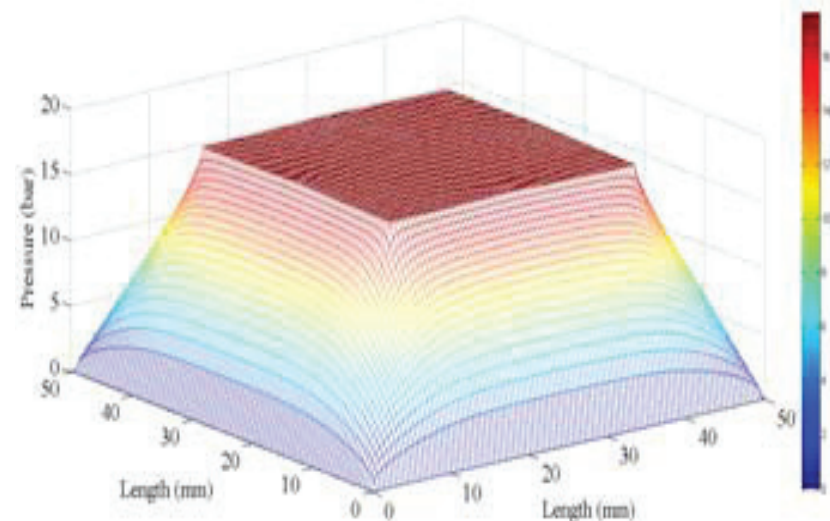

Figure 6. The pressure distribution.

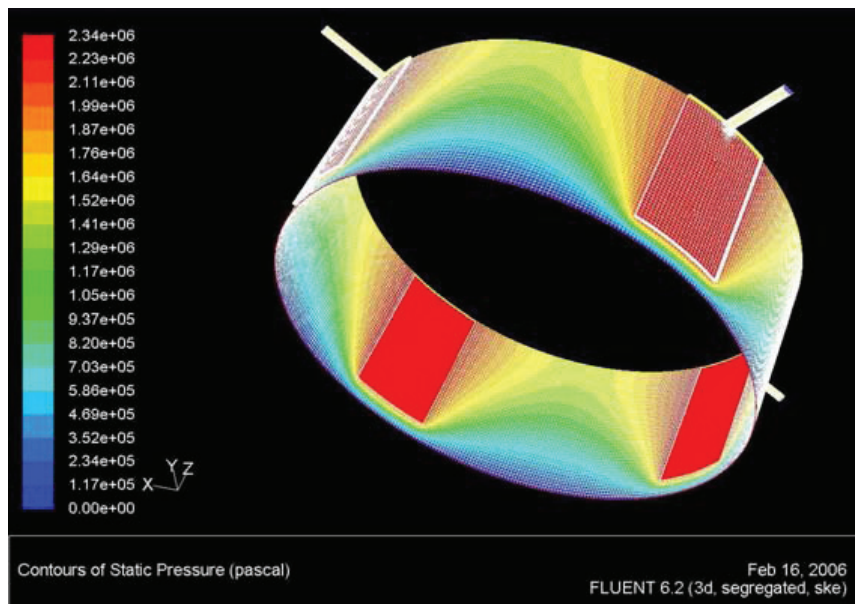

Figure 7. The temperature distribution.

thickness and bearing size. The comparison results of the bearing performance as shown in Figure 8 and Figure 9. We can found load capacity and flow rate of the proposed design are better than general hydrostatic bearing, and the stiffness and damping coefficients of the proposed design are similar to general.

(a) The load capacities of the hydrostatic bearing with different supply pressures and film thicknesses.

(b) The stiffness coefficient of the different supply pressures and film thicknesses.

(c) The flow rate of the different supply pressure and film thicknesses.

(d) The damping coefficient of the different supply pressures and film thicknesses

A pressure distribution can observe into bearing's small clearance surface, the pressure keeps constant. Analysing

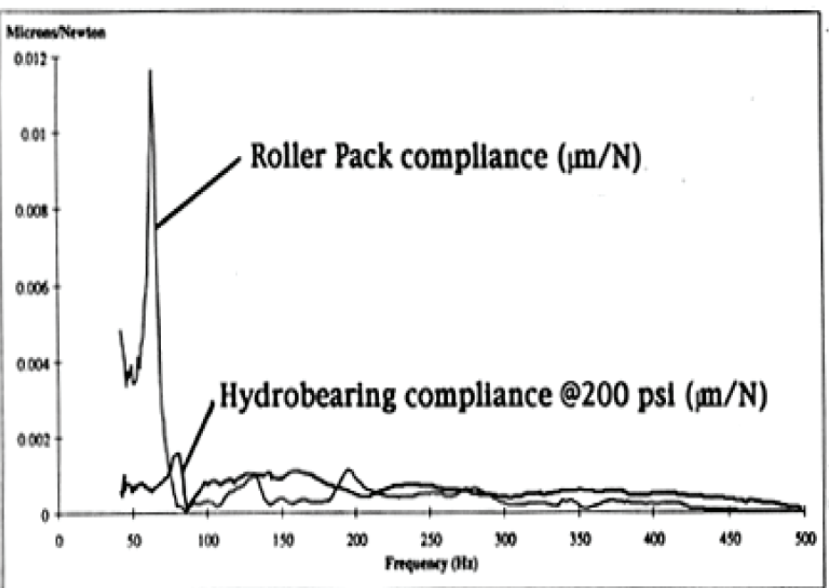

Figure 8. Fluid pressure variance with disc radius.

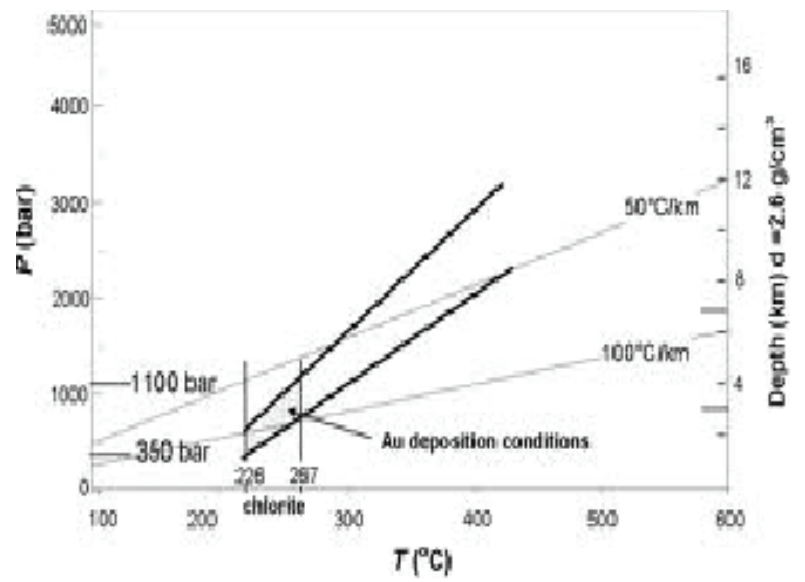

Figure 9. Fluid temperature variance with disc radius.

the pressure drop in lateral clearance, a linear distribution of pressure can be observed.

\section{Results and Discussion}

Hydrostatic bearings' test bench has been experimented, and its results are verified with analytical model. On the other hand, these results are compared with numerical model to validate the capability of this tool to design new lubricated bearings. Table- 1 shows the lubricant temperature increase when the bearing is working at $3 \mathrm{MPa}$. These results have been measured once the bearing temperature has become stabilized. This fact happens approximately 20 minutes after the bearing starts to run. The differences between experimental and numeric results are due to fluid temperature changes, and therefore viscosity variations. 
Table 1. Temperature and viscosity variations

\begin{tabular}{cccc}
\hline Temperature $\left({ }^{*} \mathbf{C}\right)$ & $\mathbf{n}$ & $\mathbf{k}$ & Viscosity $(\mathbf{c p})$ \\
\hline 26.2 & 0.42467 & 0.0765 & 281 \\
26.5 & 0.16779 & 0.4689 & 526 \\
52.4 & 0.17421 & 0.6998 & 658 \\
63.2 & 0.12362 & 1.0256 & 946 \\
78.6 & 0.21652 & 0.7986 & 1152 \\
91.5 & 0.56231 & 0.2698 & 1116 \\
105.6 & 0.41025 & 0.6002 & 452 \\
120 & 0.22351 & 0.3265 & 526 \\
136.9 & 0.63215 & 0.0465 & 439 \\
147.1 & 0.94264 & 0.0056 & 256 \\
161.3 & 0.98889 & 0.0015 & 122 \\
175.6 & 1.01256 & 0.0001 & 41 \\
\hline
\end{tabular}

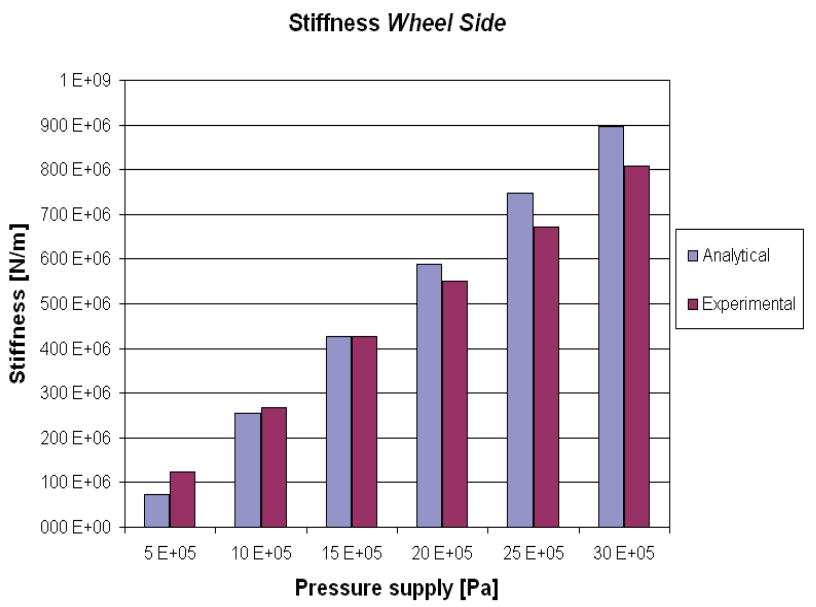

Figure 10. Pad pressure distribution pattern.

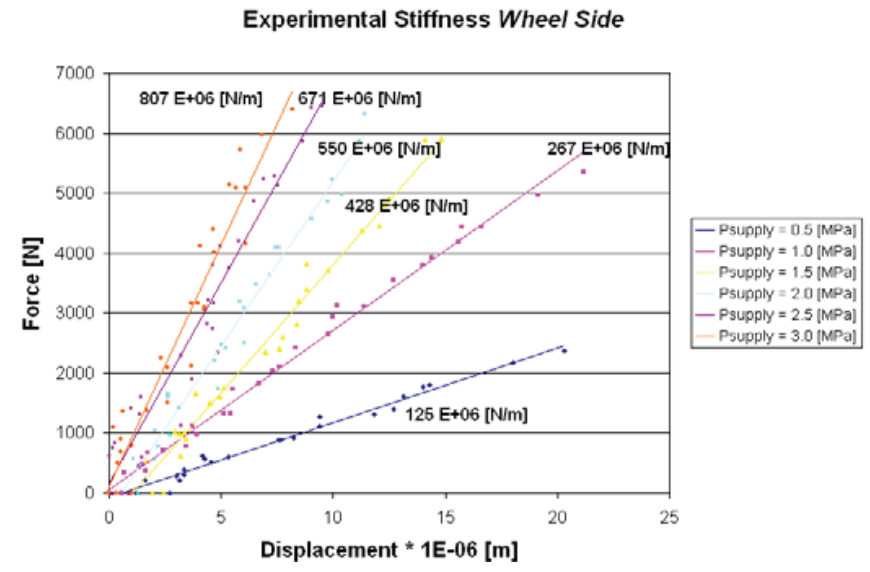

Figure 11. Pad pressure distribution using force applied.
It can be observed the force applied in the bearing and the displacement of the shaft. The relation of both is defined as experimental hydrostatic stiffness. The stiffness is compared with analytical results, and all these results are shown in Figure 10. The pad pressure distribution using force applied is as shown in the Figure 11.

\section{Conclusion}

The conclusions of this study are as follows:

(1) Through mathematic modeling, simulated by applying finite difference method, we analyzed the pressure distribution of a square hydrostatic bearing, and then from pressure distribution we calculated the performance characteristic of the proposed design such as load capacity, stiffness and damping coefficients and flow rate.

(2) We proposed a new optimization approach, which integrated different method included HTGA and RGA; it is called the HTGA/Gray method. This method can be more robust, stability, and quickly convergent. Furthermore, it can consider multiple quality characteristic in optimization problems.

(3) The parameters optimization design of a square hydrostatic bearing was done by using the HTGA/Gray method. We concluded that the performance simulation results of the proposed design are better than general hydrostatic bearing. The proposed design (HTGA/Gray method) has higher load capacity, higher stiffness and damping coefficients, lower flow rate and uniform pressure distribution.

A Hydrostatic bearings test bench has been designed, built and set-up. The test bench has been monitored with pressure, flow-rate, temperature, displacement and force sensors. Based on analytical models 8 , it has been developed software to calculate the performance of the bearing. This program is validated with experimental data of test bench. Numerical model of lubricated journal bearing has been developed. The results of this model are quite according to analytical and experimental results, but the difficulty to fit the viscosity and clearance to the working conditions, limits the use of this tool to design new, and more sophisticated hydrostatic bearings.

Once the lubrication of conventional hydrostatic bearings is analyzed the next step in this work is to develop an all-new active hydrostatic bearing. The main objective of this bearing 
is to increase the work range of actual bearings, such the maximum rotating speed as the load capacity, stiffness and dampness. Then comes the most important variables of the bearing, the viscosity, as fundamental factor because it limits the maximum speed (friction power) and gives stiffness and dampness. Thus, the control of active bearing through ferrofluids becomes a very promising field of development.

\section{References}

1. O’Donoghue J P, Rowe W B et al. (1969). Design of hydrostatic using an operating parameter. Wear, vol 14(5), 355-362.

2. Rowe W B, O'Donoghue J P et al. (1970). Optimization of externally pressurized bearings for minimum power and low temperature rise, Tribology, vol 3(3), 153-157.

3. Ghosh M K, and Majumdar B C (1980). Design of multirecess hydrostatic oil journal bearings, Tribology International, vol 13(2), 73-78.

4. Franchek N M, and Childs D W (1994). Experimental test results for four high-speed, high-pressure, orifice-compensated hybrid bearings, STLE/ASME Tribology, vol 116(1), $147-153$.

5. Sharma S C, Jain S C et al (2002). Influence of recess shape on the performance of a capillary compensated circular thrust pad hydrostatic bearing, Tribology International, vol 35(6), 347-365.
6. Sharma S C, Sinhasan R et al. (1992). Performance characteristics of multirecess hydrostatic/hybrid flexible journal bearing with membrane type variable-flow restrictor as compensating elements, Wear, vol 152(2), 279-300.

7. Singh N, Sharma S C et al. (2004). Performance of membrane compensated multirecess hydrostatic/hybrid flexible journal bearing system considering various recess shapes. Tribology International vol 37(1), 11-24.

8. Bassani R, and Piccigallo B (1992). Hydrostatic Lubrication, Elsevier Science Publishers B.V., Tribology Series, vol 22, 2-16.

9. Chen C C, Kang Y et al. (2004). The influences of orifice restriction and journal eccentricity on the stability of the rigid rotor-hybrid bearing system, Tribology International, vol 37(3), 227-234.

10. Frene J, Nicolas D et al. (1990). Hydrodynamic Lubrication, Elsevier, Tribology Series 33, vol 22, 33-73.

11. Hernandez J, Uribe-Etxeberria R et al. (2003). Simulation and experimental analysis of fluid-lubricated bearing monitoring strategies, 36th CIRP International seminar on manufacturing systems.

12. Mohsin M E, and Morsi S A(1969). The dynamic stiffness of controlled hydrostatic bearings, Journal of Lubrication Technology, vol 91(4), 597-608. 